\title{
Biochemistry of Locusts
}

\section{INSECTORUBIN: THE REDOX PIGMENT PRESENT IN THE INTEGUMENT AND EYES OF THE DESERT LOCUST (SCHISTOCERCA GREGARIA FORSK.), THE AFRICAN MIGRATORY LOCUST (LOCUSTA MIGRATORIA MIGRATORIOIDES} R. AND F.) AND OTHER INSECTS

\author{
By T. W. GOODWIN AND S. SRISUKH \\ Department of Biochemistry, The University of Liverpool
}

\section{(Received 17 March 1950)}

A major pigment component of the integument of the desert locust (Schistocerca gregaria Forsk.) and the African migratory locust (Locusta migratoria migratorioides R. \& F.) is easily extractable with cold absolute methanol or ethanol containing 1-5\% (v/v) of concentrated hydrochloric acid; it has been cursorily examined by Chauvin $(1938,1941)$, who named it acridioxanthin and considered it to be an anthocyanin derived from the food. It is a redox pigment, being yellow when oxidized and wine-red when reduced; the reduced form has occasionally been referred to as acridioerythrin by Chauvin. Becker (1939, 1941, 1942) examined the redox pigments present in the ommatidia of a number of insect species to which he gave the general term ommochromes, subdividing these into ommins and ommatins. He considered acridioxanthin to be a typical ommochrome, but Chauvin (1944) has denied this. Insect redox pigments have also been investigated by Ephrussi (1942), Ephrussi \& Herold (1944), Wald \& Allen (1946), Villee (1947), Maas (1948) and Okay (1948). The present paper reports a study of the redox pigments occurring in the integument and eyes of the desert locust and the migratory locust and in the eyes of Ephestia kühniella and Drosophila melanogaster (wild type). These pigments cannot be distinguished from each other using the experimental methods available at present; further, when the results of previous investigations are considered in the light of experience gained during the present work, one is forced to the conclusion that these pigments are also indistinguishable one from the other and from the pigments at present under consideration. A question of nomenclature thus arises. Acridioxanthin is unsatisfactory because the pigment is purple in its native state and because it is not confined to Acrididae; there is less objection to ommochrome, but this is unsatisfactory because the pigment is not confined to insect ommatidia and because the subdivision into ommins and ommatins appears to be spurious (see below); it is suggested that a more appropriate term is insectorubin.

Owing to the fact that on isolation insectorubin rapidly changes into an intractable powder, speci- mens from different sources have not been obtained in crystalline form; although this precludes final proof of the identity of different specimens, all properties point to identity. However, in the absence of crystalline specimens, it must be conceded that the pigments from various sources may differ in some minor degree. Our own experience and that of other investigators suggest that the possibility of isolation of crystalline specimens is, at the moment, somewhat remote, as the brown powder obtained is reminiscent of melanin (Tatum \& Beadle, 1942; see also below) which has defied attempts at crystallization for many years. Insectorubin, then, will serve as useful a purpose as the term melanin in indicating, if not a single pigment, then a group of extremely closely related pigments which are at the moment indistinguishable, and will perhaps prevent an unjustified multiplicity of names as further insect species are examined.

\section{EXPERIMENTAL}

As methods of extracting the integument of both species of locusts were the same, and as they yielded similar results, they will not be described separately.

The appropriate tissue was finely ground with acid-washed silver sand and was extracted with acetone to remove the carotenoids, $\beta$-carotene and astaxanthin (Goodwin \& Srisukh, 1949), and then with successive portions of $80 \%$ $(v / v)$ aqueous ethanol until no more yellow pigment was extracted. The aqueous ethanol extract was evaporated to dryness in vacuo and the residue freed from traces of carotenoids by washing with ether. The resulting brown solid was then treated according to the method described by Pryor (1940). It was found to contain two substances, one giving a green coloration with $\mathrm{FeCl}_{3}$, probably an ortho-dihydric phenol, and the other a brown material which has not been studied further. Ortho-dihydric phenols have already been reported in insects, including Locusta migratoria, by Pryor (1940). Insectorubin was then obtained by extraction of the tissue with ethanol or methanol containing $1-5 \%(v / v)$ of conc. $\mathrm{HCl}$ or with $0.5 \mathrm{~N}-\mathrm{NH}_{4} \mathrm{OH}$ or $0.1 \mathrm{~N}-\mathrm{NaOH}$. Using acid ethanol or acid methanol, the solvents are first purified by distillation after refluxing over $\mathrm{Zn}$ and solid $\mathrm{KOH}$ for $3 \mathrm{hr}$. If the solvents are not purified the wine-red extract of insectorubin is soon oxidized to the orange-yellow form. Exhaustive extraction with acid ethanol always leaves the 
Table 1. Absorption maxima of insectorubin in various solvents and after chromatographic separation and isolation in the solid form

Condition

Fresh extract (as extracted)

Reduced

Oxidized

After chromatography

Reduced

Oxidized

Isolated solid (damp)

Reduced

Isolated solid (dried)
Oxidized

$\lambda_{\max .}(\mathrm{m} \mu$.

$\begin{array}{ccccc}\mathrm{NaOH} & \text { Glacial acetic acid } & \text { Acid ethanol } & \text { Conc. } \mathrm{H}_{2} \mathrm{SO}_{4} & \text { Ethylene glycol } \\ 290,350,415 & 280,340,460-465 & 275-280,375,460 & 310,410,440,515 & 292,350,460 \\ - & - & 275-280,375,490 & - & 385,485-490 \\ - & - & 375,445-450 & - & - \\ 245,290,380 & - & 365,490 & - & - \\ 245,290,380 & - & 365,445 & - & - \\ \text { Z } & - & 275,450 & 442,504 & - \\ - & - & 275,435 & - & -\end{array}$

with amyl alcohol, and the combined extract washed many times with successive small quantities of distilled water until the washings were free from $\mathrm{Cl}^{-}$; a small amount of oxidized insectorubin was formed during the process and was lost owing to its extraction by water. The washed amyl alcohol extract was dried over anhydrous $\mathrm{Na}_{2} \mathrm{SO}_{4}$ and the bulk of amyl alcohol removed in vacuo, the last traces being removed in a stream of $\mathrm{N}_{2}$. The reddish brown amorphous product (solid $A$ ) was washed with ether and dried in a desiccator over $\mathrm{CaCl}_{2}$. the band at $275-280 \mathrm{~m} \mu$. disappears completely, the band at $375 \mathrm{~m} \mu$. becomes less pronounced, whilst that at $490 \mathrm{~m} \mu$. shifts to a lower wavelength, namely $445-450 \mathrm{~m} \mu$.

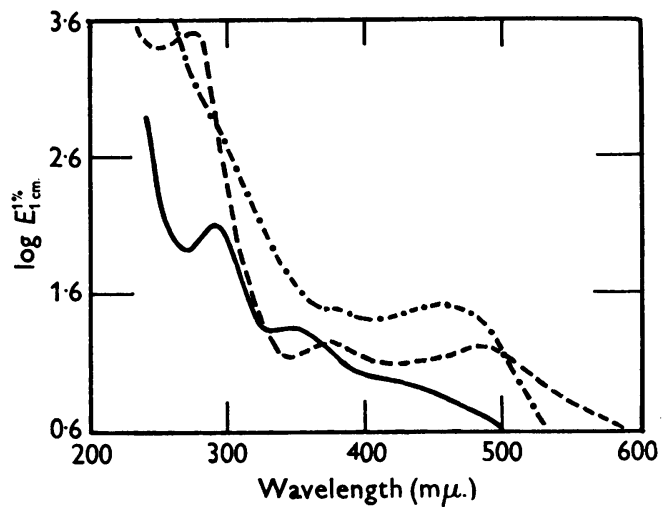

Fig. 1. The complete absorption spectrum of freshly extracted insectorubin. - - , reduced form in acid ethanol (ethanol containing $1 \%$ conc. $\mathrm{HCl}(\mathrm{v} / \mathrm{v})$ ); $-\cdot-\cdot$, oxidized form in acid ethanol; - , in $\mathrm{N} \cdot \mathrm{NaOH}$.

If insectorubin is extracted with dilute alkali a yellow solution with a pale-green fluorescence in ultraviolet light is obtained. On acidification (e.g. $\mathrm{N}-\mathrm{HCl}$ ) the yellow solution first turns red and then at about $\mathrm{pH} 2$ throws out a wine-red flocculent precipitate.

Isolation of insectorubin. Insectorubin was obtained in its reduced form as a dark-red amorphous powder in two ways. In the first process the wine-red acid-ethanol solution (1 l.) was diluted with $500 \mathrm{ml}$. of water, and $0.5 \mathrm{~g}$. of $\mathrm{Na}_{2} \mathrm{~S}_{2} \mathrm{O}_{4}$ and $50 \mathrm{ml}$. of $\mathrm{N} \cdot \mathrm{HCl}$ added. The resulting solution was extracted

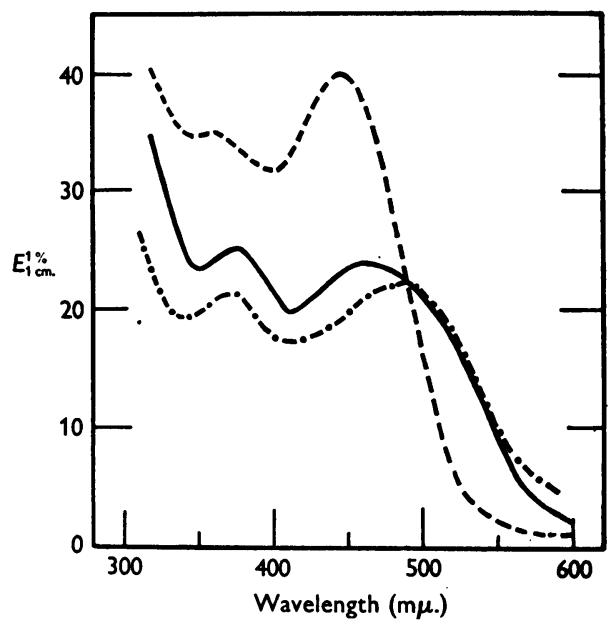

Fig. 2. The visible absorption spectrum of freshly extracted insectorubin in acid ethanol (ethanol containing $1 \%$ conc. $\mathrm{HCl}(\mathrm{v} / \mathrm{v}))$. - - - , reduced form; - - - oxidized form; - as extracted; a mixture consisting mainly of reduced insectorubin.

In the second method the acid-ethanol extract was com. pletely reduced with either $\mathrm{Na}_{2} \mathrm{~S}_{2} \mathrm{O}_{4}$ or with $\mathrm{SO}_{2}$ and made just acid to congo red paper by the addition of a saturated solution of sodium acetate. After standing overnight at room temperature, the precipitated $\mathrm{NaCl}$ was filtered off and the filtrate concentrated under reduced pressure under $\mathrm{N}_{2}$; when almost all the ethanol had been removed the solution 
was cooled and the pigment precipitated as red flocks together with a certain amount of inorganic salts. The precipitate was washed with the minimum amount of hot water to remove the inorganic salts. A portion of the wet precipitate (solid $B$ ) was examined at this stage, but the major portion was dissolved in hot methanol, filtered, and the methanol then removed in vacuo to yield a reddish brown powder (solid $C$ ) which was dried and stored in a desiccator. All attempts at crystallization failed.

The dry solids $A$ and $C$ were identical and will not be dealt with separately; the wet precipitate $(B)$, however, differed in certain important respects from the dry solids, chiefly in solubility and absorption spectra. If the newly prepared solid $B$ is shaken with acid ethanol about $90-95 \%$ dissolves; if this solution is taken to dryness and the process repeated, again only about $95 \%$ dissolves. If such an experiment is carried out with the dried material an even greater portion fails to redissolve. Further, the absorption spectrum of the material which is soluble in acid ethanol is different from that

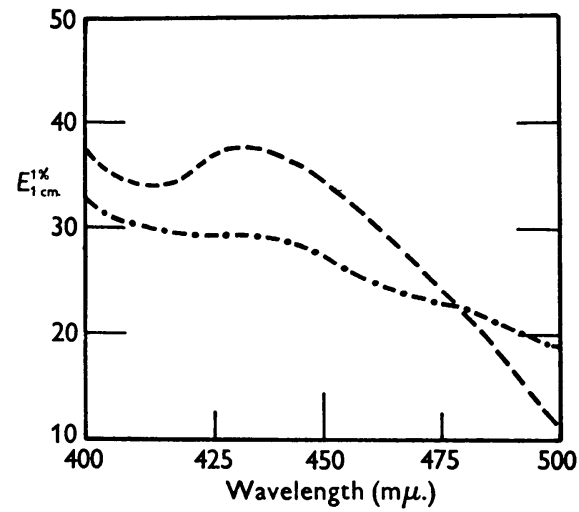

Fig. 3. The absorption spectrum of isolated aged insectorubin in acid ethanol (ethanol containing $1 \%$ conc. $\mathrm{HCl}$ $(\mathrm{v} / \mathrm{v}))$. (Compare Fig. 2.) -.-., reduced form; - - -, oxidized form.

of freshly extracted insectorubin (Fig. 3). All bands become very much less defined and the spectrum recalls that of melanin (Mason, 1948). Thus insectorubin in the solid state undergoes an irreversible change which occurs more quickly when the pigment is dry. Further evidence that insectorubin changes in the solid state is provided by observing the different spectra produced when solids $A$ and $B$ are dissolved in conc. $\mathrm{H}_{2} \mathrm{SO}_{4}$ (Fig. 4). $B$ shows two bands in the visible $\lambda \lambda_{\max } 504$ and $442 \mathrm{~m} \mu$., whilst $A$ shows only a broad inflexion between 400 and $500 \mathrm{~m} \mu$. The difference is apparent to the naked eye. Sample $B$ gives an immediate violet colour, which quickly turns red, whilst the dried specimens (samples $A$ and $C$ ) gave a brown colour with a slight reddish tinge. The spectrum of the fresh material in $\mathrm{H}_{2} \mathrm{SO}_{4}$ undergoes interesting changes on altering the concentration of the $\mathrm{H}_{2} \mathrm{SO}_{4}$; on diluting the solution to a concentration of $40 \%$ (w/v) with respect to $\mathrm{H}_{2} \mathrm{SO}_{4}$ the solution becomes dark brownish red and the band at $442 \mathrm{~m} \mu$. becomes much less well defined; on further dilution $\left(20 \%(w / v) \mathrm{H}_{2} \mathrm{SO}_{4}\right)$ the solution becomes orange and the major band is at $474 \mathrm{~m} \mu$. with a slight inflexion at $400 \mathrm{~m} \mu$. (Fig. 4). When dialysed against water, insectorubin passes through cellophan; as the pigment dialyses it is oxidized by the $\mathrm{O}_{2}$ in the water so that the colour of the dialysate is orange-yellow. In most experiments the smallamounts of insoluble pink-red material which remained in the bag had properties characteristic of the insoluble isolated solid.

Chromatographic behaviour of insectorubin. The pigment could not be effectively adsorbed on $\mathrm{Al}_{2} \mathrm{O}_{3}$, but talc was found to be a suitable adsorbent. A talc column (40-50 cm.) was repeatedly washed with acid ethanol until the filtrate was colourless. If the acid-ethanol extract of the pigment was then poured on this column and the chromatogram developed with acid ethanol, two zones appeared, the upper zone being narrow and orange and the lower zone wide and purple. Even after prolonged development with acid ethanol no further separation occurred. The pigments were extracted from the two zones with either ethylene glycol or with $0 \cdot 1 \mathrm{~N}-\mathrm{NaOH}$ and were shown by absorption spectra and redox properties to be oxidized and reduced insectorubin. The combined acid ethanol filtrates were found to contain a

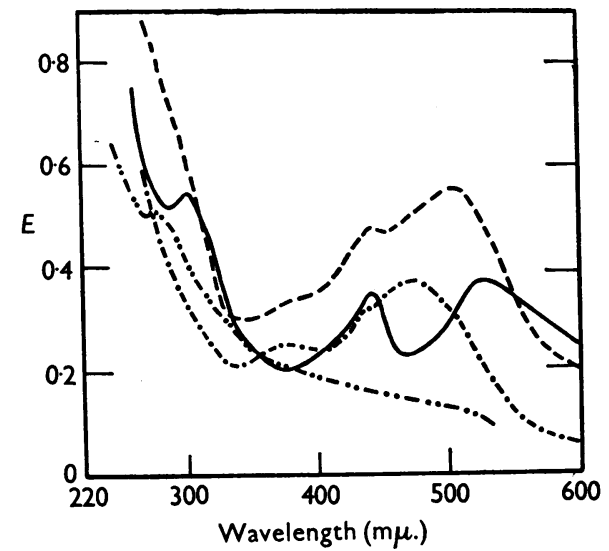

Fig. 4. The absorption spectrum of insectorubin in $\mathrm{H}_{2} \mathrm{SO}_{4}$. - , fresh sample in conc. $\mathrm{H}_{2} \mathrm{SO}_{4} ;-\cdots, \cdots$, aged sample in conc. $\mathrm{H}_{2} \mathrm{SO}_{4} ;---$, fresh sample in $40 \%(w / v) \mathrm{H}_{2} \mathrm{SO}_{4}$; $-\cdot-\cdot$, fresh sample in $20 \%$ (w/v) $\mathrm{H}_{2} \mathrm{SO}_{4}$.

minute trace of a yellow material which had no characteristic absorption spectrum and was discarded. Because of this demonstration of the essential homogeneity of the insectorubin extract, chromatography, which in this case is long and tedious, was not resorted to in the isolation of the pigment.

\section{RESULTS}

\section{Properties of insectorubin}

The chief characteristic of insectorubin is, apart from its redox properties, its failure to react with usual chemical reagents. It has been shown not to contain a phenolic hydroxyl group, a free amino group, an indole residue, a purine residue; it contains no free $\alpha$-position in a pyrrole residue nor is it a bilirubinoid or a dipyrrylmethene. Attempts to prepare by the usual procedures methyl, acetyl and benzoyl derivatives, failed. On fusion with solid potassium hydroxide, ammonia was readily liber- 
ated, and after some water had distilled over, a paleyellow oil was obtained at $112^{\circ} / 760 \mathrm{~mm}$.; no other fractions were obtained. The yellow oil, which was only obtained in small amounts, gave a positive pine splint test, an absorption spectrum $\left(\lambda_{\max .}, 260 \mathrm{~m} \mu\right.$. in $n$-hexane; $258 \mathrm{~m} \mu$. in ethanol, and $315 \mathrm{~m} \mu$. in conc. $\mathrm{H}_{2} \mathrm{SO}_{4}$ ) characteristic of pyrrole and an Ehrlich aldehyde reaction very similar to pyrrole but different from indole (Fig. 5). This latter test

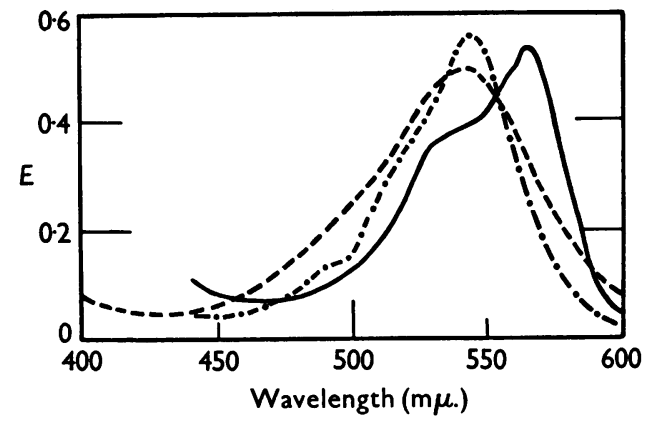

Fig. 5. The absorption spectrum of the colour produced immediately with indole, pyrrole, and the base (probably $N$-methylpyrrole) isolated from insectorubin, by Ehrlich's diazo reagent. $-\cdot-\cdot$, pyrrole; $\longrightarrow$, indole; --isolated base (probably $N$-methylpyrrole).

cannot, however, be taken as unequivocal proof of the existence of a pyrrole residue in the yellow oil, because, through the kindness of $\mathrm{Dr} R$. J. Beer, we were able to examine the reaction of a number of indole and pyrrole derivatives with Ehrlich aldehyde reagent. As these have not previously been examined the maxima of the bands produced are recorded in Table 2. It will be seen that some indole derivatives

Table 2. $\lambda_{\max }$ of the colour produced by various pyrrole and indole derivatives with Ehrlich's aldehyde reagent

(Some colours change slightly on standing.)

\begin{tabular}{lc}
\multicolumn{1}{c}{ Compound } & $\lambda_{\max }$ \\
Indole & 566 \\
5-Methylindole & 568 \\
3-Acetoxyindole & 570 \\
5:6-Diacetyl-2-methylindole & 546 \\
5-Hydroxy-2-methylindole & 540 \\
7-Methylindole & 497 \\
Pyrrole & 544 \\
4-Acetyl-3-methyl-5-phenylpyrrole & 544 \\
Yellow oil obtained from insectorubin & 544 \\
(? N-methylpyrrole) &
\end{tabular}

exhibit bands with maxima near to those of pyrrole and its derivates. These compaunds can, however, be clearly distinguished from pyrrole compounds by their direct ultraviolet absorption spectra (Srisukh, 1950).
It is also important to note that the red colour produced by the yellow oil is stable to heat, whilst the colours produced by indole and pyrrole change on warming to a purplish blue. On treatment with mercuric chloride the yellow oil yielded a crystalline compound which melted at $126-130^{\circ}$. This, together with the other available evidence cited above, indicates that the yellow oil is quite likely $N$-methylpyrrole; Fischer \& Orth (1937) state that this compound boils at $114-115^{\circ}(749 \mathrm{~mm}$. $\mathrm{Hg})$ and forms a double compound with mercuric chloride melting at $120-130^{\circ}$.

When solid insectorubin was distilled with zinc dust, two volatile fractions were collected; the first was a colourless oil which distilled over at $86^{\circ} \%$ $760 \mathrm{~mm}$. and the second a pale-yellow oil boiling at $113^{\circ} / 760 \mathrm{~mm}$. The latter possessed properties indistinguishable from those of the yellow oil just described. The colourless oil was insoluble in water and ether but soluble in other usual organic solvents, gave positive pine splint and Ehrlich $\left(\lambda_{\max .} 520 \mathrm{~m} \mu\right.$.) tests and a typical pyrrole spectrum ( $\lambda_{\max .} 272 \mathrm{~m} \mu$. in ethanol). Its boiling point suggested that it might be either haemopyrrole or cryptopyrrole; owing to its insolubility in ether the latter is ruled out and thus the limited evidence available points to its being haemopyrrole.

\section{The reddish brown pigment of locust eyes}

A large number of locust eyes, which are brown, were first extracted with acetone to remove carotenoids and then with water and ethanol, which removed two further pigment fractions (to be dealt with in a later communication). The wine-red residue was treated with cold acid methanol and the resultant extract examined in the same way as the integument extracts. A single brown pigment was isolated in small amounts which was indistinguishable from the redox pigment of the integument.

The brown pigment in the eyes of Drosophila melanogaster (wild type) and Ephestia kühniella

Eyes of these two insects were treated in the same way as locust extracts. The acid-methanol soluble pigment was, in each case, indistinguishable from the locust pigment.

\section{The pinkish purple pigment of Locusta infected with Plistophora}

When Locusta are infected with the protozoan Plistophora, small but intense pinkish purple spots appear on the integument and in the subcutaneous tissues. The pink regions of a number of infected Locusta were examined after carefully removing the surrounding tissues. All tests indicated that the pigment responsible for the pink spots was insectorubin. 


\section{The pigment in the pink faeces of locusts}

Normal locust droppings are darkish green to black in colour, but on starving the insects, these turn pink. The pink faeces were examined in the usual way and found to contain insectorubin. Up to the moment it has not been found possible to demonstrate the presence of insectorubin in normal faeces; it certainly does not occur in amounts comparable with those found in pink faeces, but it may be present in very small amounts which would be difficult to detect in the presence of relatively large amounts of chlorophyll degradation products.

\section{DISCUSSION}

It has already been pointed out in the introduction that all the insect redox pigments so far examined are, as far as can be ascertained at present, indistinguishable and that the name insectorubin is suggested for this widespread pigment. Becker (1939) who, apart from the present investigators, is the only worker to have isolated the pigment, made two observations which need consideration. In the first place he considered that a number of pigments (ommochromes) occur which can be divided into ommatins and ommins according to their molecular size. This differentiation is based on the following changes in properties; ommins appear to be more stable in alkali, reduce rather more slowly, and with concentrated sulphuric acid give a brown rather than a violet colour. The present work shows that these variations in properties can be observed merely if an extract —or more quickly a solid specimen - of insectorubin is allowed to age; insectorubin behaves as an ommatin when freshly extracted and gradually changes into an ommin on standing. Thus it appears that this differentiation is spurious and that Becker's ommins are artifacts. This interpretation is confirmed when it is considered that during the present work it was found that acid-methanol extracts of Drosophila and Ephestia eyes were indistinguishable, although Becker considers the pigment from Drosophila to be a typical ommatin (phaeommatin) and that from Ephestia a typical ommin (skotommin).

Secondly, Becker claimed that ommochromes could be benzoylated; we could not confirm this and it appears, in fact, that Becker obtained very little evidence for benzoylation. He dissolved the pigment in $2 \mathrm{~N}$-sodium carbonate, shook with benzoyl chloride, acidified and extracted with butanol; the butanol extracted a 'violet ester' which was not examined further. It seems highly likely that Becker extracted the unchanged pigment into butanol, for we have found that in butanol and amyl alcohol insectorubin is bright reddish violet.

When the locust pigment is specifically con- sidered, there appears no doubt that Chauvin's (1941, 1944) claim that insectorubin is an anthocyanin cannot be accepted. He further noted that his extracts of insectorubin gave positive reactions with Fehling's, Millon's and Van den Berg's reagents and with ferric chloride. The present work indicates that these reactions are not given by purified insectorubin. When extracting his locusts, Chauvin omitted a preliminary extraction with aqueous ethanol which removes the dihydric phenol derivatives; thus his extracts were always contaminated with these substances which would respond to the abovementioned tests. It is extremely likely that some of the extracts of insectorubin which Okay (1948) prepared from a number of insect species were also contaminated in this way.

As previously mentioned, isolated insectorubin undergoes rapid transformation into an intractable amorphous brown powder which could not be crystallized and from which no crystalline derivatives could be obtained. From restricted degradation experiments two substances were obtained which, although not unequivocally identified, appear to be $N$-methylpyrrole and haemopyrrole. These results suggest that insectorubin is a member of the pyrrole group of pigments, but it is quite evident that it is not a characteristic bilirubinoid, dipyrrylmethene or haem.

The possible presence of an $N$-methylpyrrole in insectorubin is interesting in that it could account for the characteristic spectral changes on oxidation and reduction. On reduction the absorption maximum shifts to longer wavelengths, namely from 445 to $490 \mathrm{~m} \mu$.; analogous shifts on reduction have as yet only been noted with quaternary compounds such as coenzymes I and II and nicotinamide methiodide (Karrer \& Benz, 1936). It appears that tryptophan is a precursor of insectorubin in Drosophila and Ephestia, intermediates being $\alpha$-hydroxy-tryptophan and kynurenine (see, for example, Beadle, 1945). This indicates that it is not impossible for insectorubin to contain a $N$-methylpyrrole residue for in vertebrates tryptophan can probably be converted into $N$-methylnicotinamide (but see, for example, Ellinger \& Abdel Kader, 1949). It remains to be seen whether tryptophan is the only precursor of insectorubin for there is some evidence that in producing their green pigments some insects can utilize the pyrrole residues of chlorophyll (Metcalf, 1945) and, in the case of vertebrates, it is now well established that glycine is a precursor of haem (see, for example, Bentley, 1949).

\section{SUMMARY}

1. The redox pigments occurring in the eyes and integument of the desert locust (Schistocerca gregaria Forsk.) and the African migratory locust (Locusta 
migratoria migratorioides R. \& F.) and in the eyes of Drosophila melanogaster (wild) and Ephestia kühniella have been investigated.

2. The pigments cannot be distinguished from each other. As the redox pigments reported in other insects also appear indistinguishable from our pigment, it is proposed that this widespread insect pigment be termed insectorubin.

3. Insectorubin has been isolated as a reddishbrown powder which quickly changes into an intractable dark-brown powder, reminiscent of melanin; its properties have been fully recorded.

4. It is extremely resistant to normal methods of chemical attack, but it has yielded two pyrrole derivates. These have not been unequivocally identified but appear to be $N$-methylpyrrole and haemopyrrole.

5. Insectorubin is the pigment responsible for the colour of the pink faeces produced by starved locusts and of the pink patches in the subcutaneous tissue and integument of Locusta infected with Plistophora.

6. Spectral data on the colours produced by a number of indole and pyrrole derivatives with Ehrlich's diazo reagent are recorded.

We are grateful to the Anti-Locust Research Centre for supplying material and for financially assisting this investigation; to Dr R. J. Beer for samples of pyrrole and indole derivatives; to Prof. C. Rimington for a helpful discussion; and to Prof. R. A. Morton, F.R.S., for advice and encouragement at all times.

\title{
REFERENCES
}

Beadle, G. W. (1945). Chem. Rev. 37, 15.

Becker, E. (1939). Biol. Zbl. 59, 597.

Becker, E. (1941). Naturwissenschaften, 29, 237.

Becker, E. (1942). Z. indukt. Abstamm.- u. VererbLehre. 80, 157.

Bentley, R. (1949). Rep. Progr. Chem. 45, 239.

Chauvin, R. (1938). C.R. Acad. Sci., Paris, $207,1018$.

Chauvin, R. (1941). Ann. Soc. ent. Fr. 110, 133.

Chauvin, R. (1944). Bull. Soc. zool. France, 69, 154.

Ellinger, P. \& Abdel Kader, M. M. (1949). Biochem. J. 44, 285.

Ephrussi, B. (1942). Cold Spr. Harb. Sym. quant. Biol. 10, 40.

Ephrussi, B. \& Herold, J. L. (1944). Genetics, 29, 148.
Fischer, H. \& Orth, H. (1937). Die Chemie des Pyrrols, 1. Leipzig: Akademische Verlagsgesellschaft.

Goodwin, T. W. (1950). Biochem. J. 47, 544.

Goodwin, T. W. \& Srisukh, S. (1949). Biochem. J. 45, 263.

Karrer, P. \& Benz, J. (1936). Helv. chim. Acta, 19, 1208.

Maas, W. K. (1948). Genetics, 33, 177.

Mason, H. S. (1948). J. biol. Chem. $172,83$.

Metcalf, R. L. (1945). Ann. ent. Soc. Amer. 38, 397.

Okay, S. (1948). Comm. Fac. Sci. Univ. Ankara, 1, 178.

Pryor, M. G. M. (1940). Proc. roy. Soc. 128 B, 378, 393.

Srisukh, S. (1950). (Unpublished observations.)

Tatum, E. L. \& Beadle, G. W. (1942). Growth, 6, 27.

Villee, C. A. (1947). Genetics, 32, 277.

Wald, G. \& Allen, G. (1946). J. gen. Physiol. 30, 41.

\section{Biochemistry of Locusts}

\section{INSECTORUBIN METABOLISM IN THE DESERT LOCUST (SCHISTOCERCA GREGARIA FORSK.) AND THE AFRICAN MIGRATORY LOCUST (LOCUSTA MIGRATORIA MIGRATORIOIDES R. AND F.)}

\author{
By T. W. GOODWIN \\ Department of Biochemistry, The University of Liverpool
}

(Received 25 May 1950)

The major pigment components of locusts are melanin (Chauvin, 1941), the carotenoids $\beta$-carotene and astaxanthin (Goodwin \& Srisukh, 1948, 1949), and a redox pigment, insectorubin (Goodwin \& Srisukh, 1950b). Before the general distribution of insectorubin in insects was appreciated Chauvin (1941) had termed this pigment acridioxanthin and, occasionally, acridioerythrin.

As solitary and gregarious locusts are characterized by marked colour differences (see, for example, Uvarov, 1947) it was obviously important, in investigations designed to throw light on the problem of swarming, to consider pigment metabolism in solitary and gregarious locusts under different conditions. Such an investigation concerning the carotenoids has already been described (Goodwin, 1949) and the present report deals with insectorubin.

This pigment is a pyrrole derivative of undetermined structure which has not yet been obtained crystalline owing to the rapidity with which, in the solid state, it polymerizes into an amorphous powder, reminiscent in some ways of a melanin (Goodwin \& Srisukh, 1950b). It can, however, be satisfactorily characterized spectroscopically for, when fresh, it exhibits a characteristic spectrum according to whether it is in its reduced or oxidized form. 